\title{
Silja Vuorikuru
}

\section{"Ma kymmenesti vain Sinua suutelin ja kymmenesti Urian murhasin" Aino Kallaksen kadonnut näytelmä Bathseba}

\begin{abstract}
Aino Kallas kirjoitti vuosina 1909-1910 näytelmää Bathseba, joka nimensä mukaisesti pohjautui vanhatestamentilliseen kolmiodraamaan kuningas Daavidin, sotamies Urian ja tämän vaimon Bathseban välillä. Toisen Samuelin kirjan lukuihin 11 ja 12 sijoittuvassa kertomuksessa Daavid lähettää Urian sotimaan Israelin joukkojen etulinjassa, jotta voisi tämän kaaduttua ottaa Bathseban vaimokseen.
\end{abstract}

21.9.1910 Kallas lähetti näytelmäkäsikirjoituksensa nimimerkin suojissa kirjailija, teatteriohjaaja ja estetiikan dosentti Jalmari Hahlin kommentoitavaksi. Kuukauden kuluttua saapunut vastaus ei imarrellut kirjailijaa: Hahl piti Bathsebaa novellistisena draamallisen asemesta, sen henkilöhahmoja ratkaisuineen epäuskottavina ja raamatullisten aiheiden dramatisointia vanhanaikaisena. ${ }^{1}$ (Kallas 1909-1910/1978, 494-538; päiväkirjojen käsikirjoitukset SKS KIA.) Kallas harkitsi näytelmän kirjoittamista uudelleen, mutta syystä tai toisesta työ jäi sikseen; Bathsebaa koskevat päiväkirjamerkinnät harvenevat ja loppuvat pian kokonaan.

Bathsebasta tuli paitsi julkaisematon, sittemmin myös kadonnut näytelmä. Kai Laitiselle 20.3.1953 kirjoittamassaan kirjeessä Kallas kertoo hävittäneensä Bathseban käsikirjoituksen vuosikymmeniä kirjoittamisajan jälkeen. Kai Laitinen julistaakin Bathseban kadonneeksi: näytelmästä säilyi hänen mukaansa vain kaksi laulua, jotka Kallas sittemmin julkaisi runokokoelmassa Kuoleman joutsen (1942) nimillä "Seitsemän hunnun tanssi” ja "Unhoitus" (Laitinen 1973, 163; ks. myös 1973, 267, 349; 1995, 341.) Myöhemminkään Bathsebaa ei mainita Kallaksen käsikirjoitusten joukossa, teosluetteloista puhumattakaan.

Bathseba ei kuitenkaan ollut kadonnut jäljettömiin. Vierailin elokuusta 2007 maaliskuuhun 2008 Tarton yliopistossa Virossa. Tartossa sijaitseva Viron Kirjallisuusmuseo, Eesti Kirjandusmuuseum, on Kallas-tutkijan aarreaitta: siellä säilytetään suurta osaa Kallaksen perheen kotikirjastosta ja arkistoaineistosta, museon perustajan, Aino Kallaksen aviomiehen Oskar Kallaksen testamentissaan esittämän toiveen mukaisesti (Olesk 2008). Arkistoaineistoa penkoessani löysin seasta yllättäen käsikirjoituksen Bathseba. Runonäytelmä viidessä näytöksessä, joka oli päivätty Tartossa ja Elvassa vuonna 
1909 ja jonka marginaaleja täydentävät Jalmari Hahlin lyijykynämerkinnät.

Miksi käsikirjoitusta ei ole huomattu aiemmin? Kirjallisuusmuseon vanhempi tutkija, tohtori Sirje Olesk hämmästeli tätä yhtä paljon kuin minäkin - onnitellen minua samalla lämpimästi löydöstäni. Ei saatu selville, milloin käsikirjoitus on museoon saapunut. Suuri osa Kallasten kotikirjaston materiaalia saapui Tarttoon perheen Tallinnan-kodista vuosina 1946-1949, mutta Oskar Kallaksen tiedetään toimittaneen arkistoaineistoa museoon jo vuonna 1934 (Olesk 2008).

Yllättävä löytö sai jatkoa, kun vierailin ensimmäistä kertaa paluuni jälkeen Suomalaisen Kirjallisuuden Seuran Kirjallisuusarkistossa Helsingissä vertaamassa Tarton ja Helsingin Kallas-kokoelmia toisiinsa. Tarton Kirjallisuusmuseosta kopioituihin käsikirjoituksiin lukeutui nimittäin myös Bathseban mikrofilmikopio. Kun pyysin sitä nähtäväkseni, selvisi, että olin sen ensimmäinen lukija: vaikka kopio oli luovutettu Kirjallisuusarkistoon jo 19.6.1984, mikrofilmirulla oli keväällä 2008 edelleen avaamaton.

Vuoden 1984 kopiot välitti nykyinen opetusneuvos Hannu-Pekka Lappalainen, joka tuolloin toimi Friedebert Tuglas -seuran (nykyisen Tuglas-seuran) sihteerinä. Keskustellessamme keväällä 2008 Lappalainen ei enää muistanut tarkoin kopioinnin vaiheita; aikaa niistä oli kulunut jo yli kaksikymmentä vuotta. Kopiot saatiin silloisen neuvostotasavallan ehdoilla: kopioitavaksi annettu aineisto valikoitiin KGB:n valvonnassa ja itse kopiointi tehtiin Tartossa. (Lappalainen 2008.)

Tässä artikkelissa selvitän ensiksi Bathseban kirjoittamisvaiheen eri versioita ja esitän perusteet sille, miksi löytämäni käsikirjoitus on pääteltävissä Bathseban uusimmaksi, Hahlin kommentoimaksi versioksi. Seuraavaksi selostan Bathseban sisältöä ja roolia Kallaksen tuotannossa. Lopuksi pohdin syitä sille, miksi Bathseba epäonnistui - vai epäonnistuiko se lainkaan.

\section{Bathseban monet versiot}

Aino Kallaksen päiväkirjoista - sekä julkaistuista että niiden laajemmista käsikirjoitusversioista - löytyy lukuisia merkintöjä Bathseban kirjoittamisvaiheilta. Varhaisimmassa, toukokuussa 1909 päivätyssä sisältösuunnitelmassa esiintyi vain viisi henkilöhahmoa, 16.6.1909 päivätyssä luonnoksessa henkilögalleria on kasvanut kuuteen. 27.11.1909 päiväämässään merkinnässä Kallas kertoi hävittäneensä näytelmän ensimmäisen luonnoksen, joka oli ollut kolminäytöksinen ja runomuotoinen; sen korvannut uusi versio oli viisinäytöksinen suorasanainen näytelmä. 28.1.1910 Kallas kertoo lisänneensä näytelmään uuden henkilöhahmon Mephi-Basethin ja kirjoittaneensa viidenteen näytökseen Bathseban monologin, joka alkaa sanoin "Vait', hiljaa Jesbek, hievahdusta ei...". (Kallas 1909-1910/1978, 492-541; päiväkirjojen käsikirjoitukset 1909-1910, SKS KIA.) $)^{2}$

Keväällä 2008 löytämässäni käsikirjoituksessa on yhdeksän nimettyä henkilöhah- 
moa, heidän joukossaan Mephi-Baseth, kuningas Saulin raajarikko pojanpoika. Bathseban viidennen näytöksen monologi poikkeaa päiväkirjamerkinnästä vain hitusen: Bathseba aloittaa sen sanoin "Hys hiljaa Jesbek, hievahdusta ei" (Kallas 1909, 79). Tietoa siitä, missä vaiheessa suorasanaiseksi muutettu näytelmä muokattiin taas runomuotoiseksi, päiväkirjat eivät anna.

Paitsi käsikirjoituksen myöhäiset lisäykset, myös siihen tehdyt merkinnät todistavat version uusimmaksi. Jalmari Hahl kritisoi arviossaan sanoja "suihkulähde" ja "ruokalista" pitäen niitä epäuskottavan moderneina ilmauksina; ne "eivät tunnu muinaishebrealaisilta" (Hahlin kirje Kallakselle 19.11.1910, SKS KIA). Löytämässäni käsikirjoituksessa nämä samat ilmaukset ("suihkulähteen" sijaan tosin sana "suihkukaivo") on varustettu huomautuksin "modernia" ja "tuntuu hieman modernilta 'suihkukaivo".

Löytämäni käsikirjoitus on päivätty vuodelle 1909, vaikka Kallas päiväkirjamerkintöjensä mukaan muokkasi näytelmää syksyyn 1910 asti. Päiväkirjamerkinnät osoittavat kuitenkin myös, että vuosi 1909 oli Bathseban varsinainen kirjoitusvuosi. Kallas kirjoitti jo 12.11.1909 seuraavasti: "Vielä pari päivää, ja Bathseba on valmis - tietysti vain luonnoksena, mutta täydellisenä luonnoksena". Samaan tapaan Kallas merkitsi päiväkirjaansa myös novellin "Yksi kaikkien edestä” vuoden 1912 novelliksi, vaikka se valmistui ja julkaistiin vasta vuonna 1913, novellikokoelmassa Lähtevien laivojen kaupunki.

\section{Bathseban (1909) sisältö ja rooli Aino Kallaksen tuotannossa}

Bathseba on runomuotoinen näytelmä, joka sijoittuu raamatulliseen aikaan ja miljööseen. Nämä seikat erottavat sen selvästi Kallaksen julkaistusta tuotannosta. Kallaksen lähes neljästäkymmenestä teoksesta koostuvaan tuotantoon kuuluu vain viisi runokokoelmaa; Kallaksen tärkein laji on novellistinen proosa. Myös näytelmiä on viisi; niistä neljä pohjautuu aiemmin julkaistuun proosateokseen.

Raamatulliset pastissit sekä erityyppiset intertekstuaaliset viittaukset Raamattuun, kuten henkilöhahmojen, juonen ja tematiikan kytkeminen Raamattuun esimerkiksi alluusioin ja sitaatein, ovat keskeinen osa Kallaksen proosan poetiikkaa. Kytkös Raamattuun luodaan julkaistussa tuotannossa kuitenkin aina epäsuorasti, viittaamisen ja vertautumisen kautta. Siten esimerkiksi novelli "Lasnamäen valkea laiva" (1913) on järvamaalaisen talonpoikaisyhteisön erämaavaelluskertomus 1800-luvun lopun Virossa, romaani Reigin pappi (1926) 1600-luvun Hiidenmaalle sijoitettu Jobin tarina, Mare ja hänen poikansa -näytelmä virolaisen kansanperinteen ja kristillisen tradition $\mathrm{Ma}$ (a)ria- ja Kristus-myyttien dialogia 1300-luvun Liivinmaalla. Julkaisematon Bathse$b a$ on poikkeus: sen tapahtumapaikkana on vanhatestamentillinen Jerusalem kuningas Saulin hallintovallan kukistuttua, joten ajoitukseltaan se mukailee uskollisesti toisen Samuelin kirjan aikaa ja miljöötä. 
Bathseban keskushenkilöitä ovat kolmiodraaman osapuolten lisäksi Urian äiti, Bathseban anoppi Ketura, raajarikko Mephi-Baseth, kauppias Jesbek, orja Bear, profeetta Nathan sekä Micha, yksi Daavidin lukuisista vaimoista. Lisäksi henkilögalleriaan kuuluu sotureita, orjia ja orjattaria, tanssijattaria ja unienselittäjiä.

Näytelmä alkaa kuvauksella kuningas Daavidin (näytelmässä Davidin) rakkaudesta vielä tuntematonta rakastettua kohtaan: vaimo Micha kertoo kuninkaan vaeltelevan unettomana yökaudet, lähetti on matkalla tiedustelemaan Bathseban henkilöllisyyttä, Mephi-Baseth joutuu kuninkaan rakkaushuolten kuulijaksi. Ensimmäiseen näytökseen sisältyy kaksi "Daavidin laulua tuntemattomalle rakkaalleen”, jotka ovat luonnehdittavissa psalmipastisseiksi: ${ }^{3}$

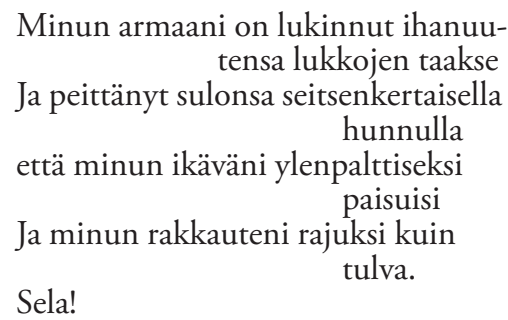

(Kallas 1909, 14)

Katso, seitsenkertainen huntu haihtuu kuin huomensumu

Ja pakenee kuin seitsemän pilveä,

Silmäni ovat sokaistut ylen suuresta valkeudesta,

Taitaako pyhä lähde niitten pimeyttä

Sela! parantaa?

(Kallas 1909, 15)

"Seitsemän hunnun" motiivi toistuu vielä Kuoleman joutsen -runokokoelman (1942) runossa "Seitsemän hunnun tanssi", jota Kai Laitinen, kuten sanottua, piti toisena kadonneesta Bathsebasta säilyneenä runona. Runot voivat toki olla samaa juurta, mutta ne poikkeavat toisistaan niin suuresti, että niitä tuskin voidaan pitää edes saman runon kahtena versiona.

Seitsemän huntua haihtuvi kuin seitsemän hattaraa, ihana olet sinä impien seassa!

Kun sa hunnun heität, niin värjyy vanha maa, tanssi, tanssi, kierrä, kierrä!

Autuuden, ah, autuuden suo purppurainen suu, menee miehen mieli, ja vaiva vaimentuu, tanssi, tanssi, kierrä, kierrä! 
Kuoleman, ah, kuoleman suo myrkkyhuuli suu.

Ihana olet sinä impien seassa!

(Kallas 1942, 55-56)

Daavid ja Bathseba kohtaavat näytelmän toisessa näytöksessä. Uria on lähdössä sotimaan Israelin joukoissa Rabbaa vastaan, ja Daavid suostuttelee Bathsebaa tulemaan sillä aikaa luokseen kuninkaanlinnaan. Bathsebaa raastaa ristiriita: toisaalta hän haluaa pysytellä kotona, Urian uskollisena aviovaimona, toisaalta hän tuntee vastustamatonta rakkautta Daavidia kohtaan. Näytelmän kolmannessa näytöksessä korostuukin Bathseban ristiriidan kuvaus: hän lähtee linnaan, mutta ajautuu vain syvemmälle epätietoisuuteensa. Näytöksessä kuullaan "Bathseban laulu”, jota Kai Laitinen piti toisena Bathseban säilyneistä lauluista. Kuoleman joutsenen runo "Unhoitus" onkin "Seitsemän hunnun tanssia" lähempänä Bathsebaa - mutta läheskään yhtenevä se ei ole:

Ah, jos unohtaa voisin

Että ennen elin,

Ah, jos syntyä saisin

Helmasta hetken tämän!

Ah, jos unohtaisivat silmät,

Minkä he nähneet ovat,

Ja unohtaisivat korvat,

Minkä he kuulleet ovat!

$\mathrm{Ah}$, jos hukkuisin häneen

Niinkuin tulvaan äyräs,

Ah, jos unohtaa voisin,

Että ennen elin...

(Kallas 1909, 44)

Ah, jos unhoittaa voisivat silmät, minkä he nähneet ovat! Ja unhoittaisivat korvat, minkä he kuulleet ovat! Ah, jos hukkua saisin, niinkuin tulvaan äyräs! Ah, jos vaipua voisin niinkuin aaltoon taivas! Ah, jos unhoittaa voisin että ammoin elin!

(Kallas 1942, 136)

Kolmas näytös huipentuu Bathseban pakoon linnasta. Tämän kuultuaan Daavid ajautuu painiskelemaan pettyneen rakkautensa, mustasukkaisuutensa ja Uriaa kohtaan heränneen vihansa välillä. Häntä käy tyynnyttelemässä vuoroin unienselittäjä, joka muistuttaa Daavidia tätä seuranneesta varjeluksesta, vuoroin profeetta Nathan, joka 
Raamatun Bathseba-kertomuksen tavoin kertoo paraabelin "köyhän miehen ainoasta karitsasta” (2. Sam. 12: 1-4). Näytelmän neljännen näytöksen lopuksi Daavid kuitenkin antaa palvelijansa vietäväksi kirjeen, jossa Uria määrätään uhkarohkean taisteluyrityksen johtajaksi. Kirjeenkirjoitus ei ole enää edes tietoinen teko, vaan kohtalonomainen tapahtuma, ylivallan ottaneen tunteen purkaus.

Mitä kirjoitinkaan

- Voin pyyhkiä sen pois ja kuitenkin

Se jossain kirjoitettu on...

ma vain

Sen jäljensin ja toinen

kaiken

aikaa

Piirrintä kuljetti...Oi, kuolemaa

On lehto täynnä, lehdet lakastuu

En katumusta tunne, suloista

On olla julma, murhan tehdessäni

Itseni löysinkö, sinetti viimeinen

Kun murtui, - tuhota, hävittää

Sisintä itseäni on, - kumpusiko

Tää teko kuten suihku suonen

Salaisen, maassa kauan piilleen.

(Kallas 1909, 71.)

Viides näytös sijoittuu kuninkaalliseen yrttitarhaan, kuten kolmaskin. Israelin soturit ja tyttäret laulavat riemulaulua Israelin joukkojen voiton kunniaksi. Ilonpito keskeytyy, kun nuori sotamies tulee kertomaan Urian kuolleen taistelussa. Bathseba saapuu paikalle Urian kohtalosta tietämättä: linnasta paettuaan hän on vaeltanut autiomaassa viiden päivän ja yön ajan Uriaa etsien. Ketura, Bathseban anoppi, paljastaa tapahtuneen hänelle, vaatien samalla "kuninkaan porttoa" kivitettäväksi aviomiehensä murhasta. Yrttitarhaan tulee kuitenkin Daavid itse, joka Bathseban tivattua asiaa paljastaa tekonsa tälle. Tämä saa Bathseban entistä vakuuttuneemmaksi omasta syyllisyydestään, ja hän heittäytyy kaivoon rakastettunsa silmien edessä, lausuttuaan: "Valkea kyyhky olin Urian. Valkeille sulilleni verta priiskui...” (Kallas 1909, 87.)

Poikkeuksellisesta tapahtumapaikastaan ja muodostaan huolimatta Bathseban kyllä tunnistaa Aino Kallaksen näytelmäksi. Rakkaus ja kuolema kiedotaan Bathsebassa erottamattomaan liittoon, kuten sittemmin Kallaksen tunnetuimmissa teoksissa, Surmaava Eros -trilogian pienoisromaaneissa 1920-luvulla. Jo Bathseban ensimmäisessä näytöksessä Daavidin neuvonantajan rooliin asettuva Mephi-Baseth antaa oraakkelimaisen 
ennustuksen siitä, että tämän luvaton rakkaus on kän̈tyvä traagiseksi:

Oi suuri David

On kaksoisia yhteenkasvaneita

Onneton luonnonoikku toinen

Hirveä leikki, julma hairahdus,

Ja toinen täydellisyys itse, taivaasta

Astunut alas mailman auringoksi.

Vaan sydänveret yhteen virtaavat

Ja lämmönlähde molemmil’on sama,

Ravinto yksi kumpaistakin ruokkii,

Jokaisen liikkeen tuntee kumpikin

Jokaisen kosketuksen, irti koskaan

Ei toisistansa pääse...

[- - ]

Yhtaikaa syntyi David, sielussasi

Rakkaus, murhanhimo...

(Kallas 1909, 18.)

Nimihenkilö Bathsebaa voidaan pitää esikoisena Kallaksen kaksijakoisten, entisestä elämästä uuteen, toisenlaiseen pyrkivien sankarittarien joukossa (vrt. Rojola 1995, xiii). Uusimman tutkimuksen Kallaksen proosatuotantoon liittämät teemat - kuten naisen seksuaalinen halu ja sen kontrolli, naiselle määritellyt kulttuuriset tilat ja kapinointi niitä vastaan, "uuden naisen" esittäminen muinaisessa, historiallisessa kontekstissa - esiintyvät jo varhaisessa Bathsebassa, jossa ne ensimmäistä kertaa Kallaksen tuotannossa esitetään näin hallitsevina teemoina (vrt. Melkas 2006, 42, 73-75, 181). Julkaisematon Bathseba punoutuu osaksi Kallaksen julkaistua tuotantoa. Kuten "Lasnamäen valkean laivan” Maie (ja hetkellisesti myös Sudenmorsiamen Aalo), myös Bathseba pyrkii palaamaan kotiinsa elettyään hetken hurmiossa; vaatimus palata entiseen elämään varjostaa jokaista hetkeä linnassa. Uria luonnehtii vaimoaan samoin määrein kuin Reigin papin minäkertoja Paavali Lempelius vaimoaan Catharina Wyckeniä: kummatkin näyttäytyvät aviomiehilleen viileinä ja pidättyväisinä, aviomiestensä hyväilyihin harvoin suostuvina. Toisaalta Bathseba on arvoituksellinen ja unelmoitu kuin Barbara von Tisenhusen, jota verrataan "tuntemattomaan kukkaan"; Uria kutsuu Bathsebaa "siniseksi kukakseen", romanttisen kaipuun symboliksi. Ja Bathseban sanat rakkaudentunnustusta kerjäävälle Daavidille sopisivat myös Maien, Barbaran, Catharinan ja Aalon huulille.

Ah, kuningas, katkaistu kahtia

On elämäni, kahta elämää,

Yhtaikaa elän, unta toinen lie,

Ja toinen totta, - mutta kumpiko,

En tiedä...Luotani kun loittonet

Vain harhaks haihdut, unikuvaks vain,

Kuin aavikolla vaeltajan silmään 
Hehkuva helleilman kaukaisen

Kohottaa kangastukset, - niin

Hämärryt multa... myös häivyt

(Kallas 1909, 45.)

Kolmiodraamallinen asetelma, balladin peruskaava, ${ }^{5}$ toistuu Bathseban jälkeen Reigin papissa: nuori papinrouva rakastuu apupappiin ja pakenee tämän kanssa sinänsä kiintyneen, mutta hallitsevan ja ymmärtämättömän aviomiehen luota. Väkivaltainen kuolema, Surmaava Eros -trilogian sankarittarien maksama hinta kielletystä tunteesta, on myös Bathseban osa; toisin kuin nämä, hän kuitenkin heittäytyy kuolemaan itse. ”Ma kymmenesti vain Sinua suutelin ja kymmenesti Urian murhasin", kuuluu Bathseban synnintunnustus (Kallas 1909, 87).

\section{Epäonnistunut Bathseba?}

Bathseban tarina ei jättänyt Aino Kallasta rauhaan. Jo vuonna 1905 hän oli julkaissut näytelmämuotoisen novellin "Bathseba Saarenmaalla" (novellikokoelmassa Meren takaa II), josta dramatisoi samannimisen näytelmän vuonna 1932. ${ }^{6}$ Vuoden 1909 Bathsebaan näillä oli lähinnä aiheyhteys: Bathseba Saarenmaalla siirtää raamatullisen kolmiodraaman asetelman 1800-luvun Viroon.

Raamatulliseen miljööseen sijoitettu raamatunkertomuksen laajennus oli poikkeus Kallaksen tuotannossa, mutta ei niinkään aikansa suomalaisessa kirjallisuudessa. Tähän myös Hahl viittasi kritiikissään: Raamattuun pohjautuvaa kaunokirjallisuutta oli viime vuosina julkaistu paljon, lukeva yleisö oli jo kyllästymässä siihen. Ennen muuta Volter Kilven esikoisteos Bathseba. Daavidin yksinpuheluja itsensä kanssa (1900) oli herättänyt suurta huomiota. ${ }^{7}$ Hahlin havainto ei ollut perätön: 1800-luvun lopun ja 1900-luvun alun suomalaisessa draamakirjallisuudessa (ja myös lyriikassa) raamatullisten aiheiden käyttö oli valtavan suosittua (Riikonen 2003, 107, 114). Bathseban lähivuosina ilmestyivät mm. Johannes Linnankosken Ikuinen taistelu (1903), Jeftan tytär (1911) ja Simson ja Delila (1911). ${ }^{8}$

Mitä mieltä olla Hahlin kritiikin yksityiskohdista? Hahl moitti Kallasta anakronismeista, mutta tunsiko hän riittävästi sitä raamatullista kieltä, jota Kallas Bathsebassa tyylittelee? Esimerkiksi sopii (viidennessä näytöksessä esiintyvä) sana "lipilaari”, jonka arvioija on varustanut kysymysmerkillä. Sana kuitenkin esiintyy vielä ns. vanhassa kirkkoraamatussa (1776); sittemmin se korvattiin sanalla "lavertelija" (esim. Ap.t.17-18) (Ikola 1992, 55). Kallaksen "arkaisoiva”, ennen muuta vanhahtavaa raamatullista kieltä tyylittelevä kielenkäyttö esiintyy ensimmäisiä kertoja juuri Bathsebassa, jossa veri "priiskoo", uhri annetaan "templissä" ja jauhoja mitataan "epha-mitalla”. Näytelmässä operoidaan alluusioin, jotka kohdistuvat sekä Vanhaan että Uuteen testamenttiin: ruu- 
kunsirpaleet kuvastavat onnettomuutta kuin Jobin kirjassa, ${ }^{9}$ ja langennut etsii parantavaa Beteshdan lähdettä, jonka enkeli saa kuohumaan. Daavid mainitaan sekä Goljatin kukistajana että Joonatanin rakastettuna.

Mitä ajatella suihkukaivosta, joka Hahlin mielestä ei sopinut muinaisheprealaiseen maisemaan? Itse kytkisin sen näytelmän kaivomotiiviin, joka toistuessaan saa johtomotiivin piirteitä. ${ }^{10}$ Bathseba ja Daavid kohtaavat ensimmäistä kertaa kaivolla kuten Raakel ja Jaakob (Israel); kummassakin kertomuksessa tämä ensikohtaaminen sitoo rakastavaisten kohtalot toisiinsa. Daavidin kohdattuaan Bathseban on mahdotonta enää asettua alamaisen aviovaimon osaan: Urian jalkojen pesu kaivon äärellä ei onnistu, vaan vesiastia särkyy sirpaleiksi. Urian petettyään Bathseba uskoo olevansa loppuikänsä saastainen: hänen puhdistautumiseensa ei riitä Jordanin vesi eivätkä Jerusalemin kuivuneet kaivot. Vettä täynnä oleva kaivo ei kuitenkaan symboloi elävää vettä ja synneistä vapautumista, vaan syvyyden kaivoa, tuhoa ja kadotusta, johon Bathseba heittäytyy. ${ }^{11}$

Täydellinen näytelmä Bathseba ei toki ole. Hahlin kritiikkiä henkilöhahmojen epäuskottavuudesta ei voida täysin sivuuttaa: esimerkiksi raajarikko Mephi-Baseth vuoroin kehottaa Daavidia houkuttelemaan Bathseba itselleen, vuoroin tuomitsee teon. Ristiriita jää selittämättömäksi, Mephi-Baseth kiinnostavuudestaan huolimatta hiukan hahmottomaksi. Käsikirjoituksessa on myös luonnosmaista horjuntaa: Daavidin vaimon nimi kirjoitetaan vuoroin nimiasuissa "Micha" ja "Michal", tätä perustelematta. ${ }^{12}$ Silti on samaan aikaan houkuttelevaa ja surullista leikitellä ajatuksilla, millainen näytelmä Bathsebasta myötämielisemmän kriitikon ohjauksessa olisi voinut tulla, ja millä tavoin sen julkaiseminen täydentäisi Kallaksen tuotantoa.

Jälkimmäinen ajatus on tosin mahdollista toteuttaa vielä nytkin.

\section{Viitteet}

\footnotetext{
${ }^{1}$ Sama syytös kohtasi Kallaksen vuonna 1935 julkaisemaa näytelmää Mare ja hänen poikansa; Kaarlo Marjanen piti näytelmää pikemminkin novellistisena kuin draamallisena. Kallas kirjoitti tuohtuneena ystävälleen, kriitikko Anna-Maria Tallgrenille 3.11.1935: "Olen valmis mihin kärsimykseen ja vaivaan tahansa, oppiakseni näytelmätekniikan, - onko todella mahdollista, että Mare on novellistinen? Päätäni huimaa, en ymmärrä sitä. Selitä Sinä. Minun täytyy oppia draaman lait.” (Vuorikuru 2008, 234.)

${ }^{2}$ Kallakselle oli ominaista kirjoittaa jopa kokonaisia käsikirjoituksia uudelleen. Esimerkiksi romaanista Reigin pappi on olemassa kaksi versiota, vuoden 1925 julkaisematon käsikirjoitus ja vuonna 1926 julkaistu romaani. Versioiden eroja, lisäyksiä ja poistoja on yksityiskohtaisesti selvittänyt Kai Laitinen (1995, 156-166).

${ }^{3}$ Kristillisessä traditiossa kuningas Daavidia pidettiin pitkään Raamatun psalmien keskeisenä kirjoittajana; monien psalmien alaotsikkona onkin "Daavidin laulu”.

${ }^{4}$ Runonsäkeiden jako riveille on käsikirjoituksen mukainen.
} 
${ }^{5}$ Kai Laitinen pitää "balladikaavaa" Kallaksen 1920-luvun proosan tunnuspiirteenä; Kallaksen 1920-luvun pienoisromaaneita kutsutaankin usein "proosaballadeiksi" (Laitinen 1995, 104108).

${ }^{6}$ Tauno Pylkkänen sävelsi Bathseba Saarenmaalla -teokseen pohjautuvan pienoisoopperan vuonna 1940.

${ }^{7}$ Aino Kallas toteaa Kilven Bathsebasta 27.12.1909: "Tahtoisin lukea Volter Kilven Bathseban. Olen siitä aikoinani lukenut vain alun. Tulleeko se häiritsemään työtäni - en tiedä.” (Kallas 1909-1910/1978, 510.)

${ }^{8}$ Myös Kallas suunnitteli Bathseban kirjoittamisaikana Simson ja Delila -aiheista teosta, mutta syystä tai toisesta se jäi kirjoittamatta (Päiväkirjojen käsikirjoitukset 1909 ja 1910, SKS KIA).

${ }^{9}$ Särkyvä ruukku tai saviastia on myös Raamatussa ja kristillisessä runokielessä ihmisen symboli. Jumala esitetään savenvalajana, jolla on valta muovata ja murskata ruukku mielensä mukaan. Sudenmorsiamessa (1928) saven ja savenvalajan metaforat käännetään nurin: savenvalaja onkin Saatana, ja noidat ovat savi.

${ }^{10}$ H. K. Riikonen analysoi kaivomotiivin käyttöä symbolina 1. Mooseksen kirjassa (26: 15-21; 29: 2-10; 37: 24-29) ja Thomas Mannin Joosef-sarjassa (Joseph und seine Brüder) (Riikonen 2002, 94-95).

${ }^{11}$ Kaivomotiivi esiintyy metaforisena myös Kuoleman joutsenessa, joka - kuten todettua - on velkaa Bathseballe. Psalmien ja Valitusvirsien kieltä tyylittelevässä runossa "Valitus" lausutaan: "Syvään kaivoon Sinä minut syöksit, / etten minä muuta näkisi kuin murheeni muodon." (Kallas 1942, 70-71.)

${ }^{12}$ Raamatussa henkilöistä käytetään tosin eri nimiä elämäntilanteen ja roolin vaihtuessa (esim. Abram - Abraham, Sarai - Saara, Jaakob - Israel). Bathsebassa tällaista syytä ei kuitenkaan esitetä.

\section{Lähteet}

\section{Painamattomat}

KAllas, AINO I909: Bathseba. Runonäytelmä viidessä näytöksessä. Tartto - Elva. (KM EKLA)

KALLAS, AINO I909-I9I0: Päiväkirjojen käsikirjoitukset. (SKS KIA)

LAITINEN, Kai 2008: Puhelinkeskustelu professori Kai Laitisen kanssa 27.2.2008.

LAPPALAINEN, HANNU-PEKKA 2008: Sähköpostikeskustelu opetusneuvos Hannu-Pekka Lappalaisen kanssa 5.3.2008.

OLESK, SIRJE 2008: Keskustelut tutkija, FT Sirje Oleskin kanssa helmi- ja maaliskuussa 2008 .

\section{Painetut}

IKOLA, OSMO I 992: Raamatun vaikutus kirjasuomeen. Biblia 350. Suomalainen Raamattu ja Suomen kulttuuri. Helsinki: Suomalaisen Kirjallisuuden Seura. 51-59.

KALlAS, AINO I942: Kuoleman joutsen. Helsinki: Otava. 
KALLAS, AINO I978 / I952-I954 : Elämäni päiväkirjat. Osa I : vuodet 1897-1916. Helsinki: Otava.

Laitinen, KaI I973: Aino Kallas 1897-1921. Tutkimus hänen tuotantonsa päälinjoista ja taustasta. Helsinki: Otava.

Laitinen, Kai I995: Aino Kallaksen mestarivuodet. Tutkimus hänen tuotantonsa päälinjoista ja taustasta. Helsinki: Otava.

MelKas, KUKKU 2006: Historia, halu ja tiedon käärme Aino Kallaksen tuotannossa. Helsinki: Suomalaisen Kirjallisuuden Seura.

NUORTEVA, JUSSI I 992 (тоIм.): Biblia 350. Suomalainen Raamattu ja Suomen kulttuuri. Helsinki: Suomalaisen Kirjallisuuden Seura.

RIIKONEN, H.K. 2003: Raamattu ja kirjallisuus: lähtökohtia ja esimerkkejä. Raamattu ja länsimainen kulttuuri. STKS:n symposiumissa marraskuussa 2002 pidetyt esitelmät. Toim. Lassi Larjo. 92-119. Helsinki: Suomen Teologinen Kirjallisuusseura.

vUOrikuru, SILJA 2008: Elämisen taiteesta. Aino Kallaksen ja Anna-Maria Tallgrenin kirjeenvaihtoa kolmelta vuosikymmeneltä. Helsinki: Otava.

Lyhenteet

KM EKLA = Kirjandusmuuseumi Eesti Kultuurilooline Arhiiv. (Tartto)

SKS KIA = Suomalaisen Kirjallisuuden Seuran Kirjallisuusarkisto. (Helsinki) 